\title{
Temperature-dependent energetics of Chaoborus populations: hypothesis for anomalous distributions in the great lakes of East Africa
}

\author{
Kathleen M. Halat ${ }^{1} \&$ John T. Lehman \\ Department of Biology, Natural Science Building, University of Michigan, Ann Arbor, MI 48109, USA \\ ${ }^{1}$ Present address: Department of Environmental Science, Policy \& Management, University of California, \\ Berkeley, CA 94720, USA
}

Received 16 February 1995; revised 14 November 1995; accepted 29 November 1995

Key words: Chaoborus, energetics, temperature

\begin{abstract}
Chaoborus, the phantom midge (Insecta, Diptera, Chaoboridae), has a widespread distribution, commonly occurring in lakes and ponds all over the world. In the great lakes region of East Africa Chaoborus is present in Lakes Victoria, Albert, Edward, Malawi and George, but absent from Lakes Tanganyika, Kivu and Turkana. Tropical lakes typically have water temperatures in the range of $22-26^{\circ} \mathrm{C}$ year round. Lakes Tanganyika and Kivu have only $20 \%$ of their bottom sediments oxygenated during full circulation, contrary to $95-100 \%$ in all of the other lakes, excluding Lake Malawi (45\%) (Hecky \& Kling, 1987). Planktivorous fish are present in all lakes (Lehman, 1995). We hypothesized that the absence of Chaoborus larvae from some lakes of East Africa may be the result of interaction among high temperatures, low oxygen levels, and fish predation.

We developed a model to estimate energetic costs for Chaoborus larvae at temperatures greater than $14{ }^{\circ} \mathrm{C}$. We hoped to shed light on the bioenergetics of Chaoborus populations, and the possibility that extant distributions of Chaoborus larvae are the result of energetic constraints.

We found that relative respiratory and growth costs of Chaoborus larvae are highest in the early stages of development. We estimated that non-feeding instar I larvae living in $25^{\circ} \mathrm{C}$ water will starve to death in less than one day. It is possible that Chaoborus populations are prevented from establishing in certain areas because high energetic costs condemn young larvae to death by either predation or starvation.
\end{abstract}

\section{Introduction}

Chaoborus, the phantom midge (Insecta, Diptera, Chaoboridae), has a cosmopolitan distribution. The winged adult stage has allowed Chaoborus to disperse into the majority of lentic systems worldwide, where its larvae are important predators. However, Chaoborus is not present in all lakes. The reasons for the discontinuous distribution of Chaoborus are a subject of debate. Eccles (1985) suggested that high salinities may exclude chaoborids from certain East African lake habitats. High temperatures, low oxygen concentrations, and fish predation (Pope et al., 1973; Northcote et al., 1978) are other possible factors limiting the distribution of Chaoborus. At warm water temperatures, the oxygen demand of Chaoborus crystallinus larvae is elevated and the development time is decreased compared to demands at cooler temperatures (Ratte, 1984).

In tropical systems, year round water temperatures average $22-26{ }^{\circ} \mathrm{C}$ or more. Respiratory and growth demands of Chaoborus at warm temperatures may strain rates of possible energetic input. In order to meet energetic demands, larvae may have to spend most of their time foraging and may have little scope to seek refuge from predators. Chaoborus larvae in high temperature environments, moreover, may be under too much energetic stress to survive conditions of temperature anoxia.

Chaoborus larvae exhibit the four stages typical of a holometabolous insect life cycle, egg, larva, pupa, and adult. The larval stage consists of four discrete instars, instars I and II in which larvae are plankton- 
ic, and instars III and IV in which larvae exhibit diel vertical migration and spend a considerable amount of time in the sediments (Stahl, 1966). Chaoborus larvae in Lake Victoria reside near the bottom of the lake (approximately $55 \mathrm{~m}$ ) during the day and up at the surface during the evening (MacDonald, 1956). Adults are short-lived and typically do not feed.

Third and fourth instar Chaoborus larvae usually spend the daylight hours in the sediments in temperate (Swift, 1976) and tropical lakes (MacDonald, 1956). It is important to the survival of these larvae that either the bottom waters are oxygenated, or that the larvae are able to withstand periods of temporary anoxia. At high temperatures, the energetic demands of respiration may be too great for the larvae to withstand prolonged periods of temporary anoxia. If there is no available oxygen in the sediment, the larvae may have to remain in the water column. Larow (1970) found that Chaoborus punctipennis larvae in low oxygen conditions (3\% saturation), showed an increase in activity by 1.82 -fold over larvae in higher oxygen conditions (68-90\% saturation), and the former larvae remained planktonic for a longer period. Larvae that remain in the water column are more susceptible to fish predation. The interaction between fish predation, food availability, and oxygen demands at high temperatures may exclude Chaoborus from establishing populations in certain environments.

In the great lakes region of East Africa Chaoborus is found in Lake Victoria, Lake Albert, Lake Edward, Lake Malawi and Lake George. Because of the adult winged stage, Chaoborus should be able to disperse throughout the region. However, Chaoborus is absent from Lake Tanganyika, Lake Kivu, and Lake Turkana. Lakes Kivu and Turkana have much higher conductivities, $1300 \mu \mathrm{S}$ and $3000 \mu \mathrm{S}$ respectively, than the other lakes where conductivities are less than 1000 $\mu \mathrm{S}$ (Lehman, 1995). Lake Tanganyika and Lake Kivu have only $20 \%$ of their bottom sediments oxygenated during full circulation; the others, except for Lake Malawi (45\%) have $95-100 \%$ of the bottom sediments oxygenated during full circulation (Hecky \& Kling, 1987). Planktivorous fish are present in all forementioned African Lakes (Lehman, 1995) including Lake Kivu in which Limnothrissa was introduced during the 1980's.

We developed a model to evaluate the effect of temperature on the energetic demands of a generalized Chaoborus larvae. The model calculates minimum daily ingestion rate required by a Chaoborus larva at different, constant temperatures $\left(>14^{\circ} \mathrm{C}\right)$. We wanted to quantify respiration and growth demands of Chaoborus at warm temperatures, $22-25^{\circ} \mathrm{C}$, to help evaluate the hypothesis that bioenergetics may constrain the distribution of the taxon and may help explain the apparent absence of Chaoborus from certain lakes in the East African region.

\section{Methods}

We calculated daily ingestion rate required by Chaoborus larvae at different, constant temperatures according to the general mass balance equation

$$
\mathrm{IR}=(R+G) \div \mathrm{AE},
$$

where

$$
\begin{aligned}
\mathrm{IR}= & \text { ingestion rate ( } \mu \mathrm{g} \text { carbon/day) } \\
R= & \text { respiration rate }(\mu \mathrm{g} \text { carbon/day) } \\
G= & \text { growth rate }(\mu \mathrm{g} \text { carbon/day); } \\
\mathrm{AE}= & \text { assimilation efficiency, approximately } 0.8 \\
& \text { for Chaoborus trivittatus fed on small food } \\
& \text { items (Giguere, 1981). }
\end{aligned}
$$

Our estimate of ingestion rate can be considered conservative because we do not account for the activity rate of Chaoborus larvae. Because we obtained most of our data from the literature, it was sometimes necessary to use data from different species of Chaoborus to develop our model. We used data on Chaoborus from studies conducted in East Africa or in other tropical regions as much as possible.

\section{Respiration}

We expressed respiration according to the variables of larval weight ( $\mu \mathrm{g}$ carbon) and water temperature $\left({ }^{\circ} \mathrm{C}\right.$ ). Berg \& Jonasson (1965) measured the respiration rate of Chaoborus flavicans larvae at different, constant temperatures $\left(8-24^{\circ} \mathrm{C}\right)$. We optically scanned and digitized data points for respiration rates at certain temperatures from fig. 6 of Berg \& Jonasson (1965) using a Microtek $600 \mathrm{G}$ flatbed digital scanner. We expressed the measured respiration rates, $R_{\mathrm{O}}$, in terms of $\mu \mathrm{g}$ carbon/day, according to the following relationship:

$$
R_{\mathrm{C}}=\left(R_{\mathrm{O}} * 24 * 12 \mathrm{gC} * \mathrm{RQ}\right) \div 22.4 \text {, }
$$

where 
$R_{\mathrm{O}}=$ Respiration rate, $\mu \mathrm{L}$ oxygen/hour;

$R_{\mathrm{C}}=$ Respiration rate, $\mu \mathrm{g}$ carbon $/$ day;

$\mathrm{RQ}=0.949$, standard value for ammonotelic animals (Downing \& Rigler, 1984).

We fit the temperature and oxygen consumption data to an exponential function $\left(n=8, R^{2}=0.993\right)$ using SYSTAT version 5.0.

$$
R_{\mathrm{C}}=\alpha * W^{\beta} * \mathrm{e}^{K * T},
$$

where

$$
\begin{aligned}
W= & \text { dry weight of a larvae }(\mu \mathrm{g} \text { carbon }) \\
\beta= & 0.75, \text { standard value for poikilotherms } \\
& \text { (Peters, 1983); } \\
T= & \text { temperature }\left({ }^{\circ} \mathrm{C}\right) \\
\alpha= & 0.0272(\mathrm{SE}=0.0003) \\
k= & 0.143(\mathrm{SE}=0.008)
\end{aligned}
$$

\section{Growth}

We expressed growth according to the variables of larval weight, water temperature, and relative age of a larva in its life cycle. Total development time is influenced by temperature. Ratte (1984) measured total development time of Chaoborus crystallinus larvae from the egg through the fourth and final larval instar at different temperatures $\left(14-27^{\circ} \mathrm{C}\right)$. We scanned and digitized data points for development rates $\left(\right.$ day $^{-1} * 100$ ) at fixed temperatures from fig. 2.3 of Ratte (1984). We fit the temperature and development data to a linear regression model ( $n=5, R^{2}=0.998$ ) to obtain the following equation:

$$
D=100 \div(0.254 * T-2.04)
$$

where

$$
\begin{aligned}
& D=\text { total development time (days); } \\
& T=\text { temperature }\left({ }^{\circ} \mathrm{C}\right) \text { for temperatures }>8^{\circ} \mathrm{C} .
\end{aligned}
$$

In order to facilitate calculations, it is convenient to express the age of a larva in units of relative time, $t^{\prime}$, scaled as a fraction of total development time. We assumed that larval instar durations scale linearly with total development time, so that the percentage of time spent in each instar is constant, regardless of total development time. Because our model is for a tropical chaoborid, the development times that we used in our simulations ranged from 23-57 days.

We used length, instar, and duration of instar data for Chaoborus anthracinus from Lake Victoria, Ugan- da (MacDonald, 1956) to develop an equation expressing growth of a Chaoborus larva over time. MacDonald (1956) found that the approximate duration of the egg stage and four instars was as follows, egg: $2-4$ days, instar I: 4-6 days, instar II: 6-10 days, instar III: 12-16 days, and instar IV: $25-30$ days, We converted total lengths of Chaoborus larvae as given by MacDonald (1956) to standard lengths, the length between the midpoints of each segment containing an air bladder (Lewis, 1975). We measured thirty Chaoborus larvae (lengths ranging from 4.1-8.1 mm) taken from Lake Victoria, Uganda on August 24, 1992, obtaining an average ratio of standard length/total length $=0.6714$ ( $\mathrm{SD}=0.056$ ). We converted standard lengths $(\mathrm{mm})$ into dry weights (mg) according to the following relationship for Chaoborus larvae (Lewis, 1975):

$$
\log (Y)=3.10 * \log (X)-2.71
$$

where

$$
\begin{aligned}
& Y=\text { dry weight }(\mathrm{mg}) \\
& X=\text { standard length of a larva }(\mathrm{mm}) .
\end{aligned}
$$

We wanted to express the model in terms of carbon thus, we converted dry weights to $\mu \mathrm{g}$ of carbon assuming $50 \%$ of the dry weight can be attributed to carbon. We used a nonlinear regression model in SYSTAT to fit the data for mass in carbon and time to the following equation $\left(n=9, R^{2}=0.950\right)$ :

$$
C=C_{\mathrm{O}} * \mathrm{e}^{\alpha *\left(1-\mathrm{e}^{-\lambda * t^{\prime}}\right)},
$$

where

$C=$ total carbon accumulation at age $t^{\prime}$;

$C_{\mathrm{O}}=0.251 \mu \mathrm{g} \mathrm{C}$, egg weight of a Chaoborus anomalus egg expressed in $\mu \mathrm{g}$ carbon (McGowan, 1974);

$t^{\prime}=$ unit of relative age;

$\gamma=5.633(\mathrm{SE}=1.365)$;

$\alpha=2.874(\mathrm{SE}=0.149)$.

Equation 6 can be rearranged algebraically to express relative age as a function of carbon content,

$$
t^{\prime}=-\frac{1}{\gamma} * \ln \left[\frac{\alpha-\ln \left(\frac{C}{C_{0}}\right)}{\alpha}\right]
$$

We used Microsoft Excel to calculate growth, the change in body carbon mass of a Chaoborus larva over time. Total development time, as calculated from Eq. 4 , was divided into 40 equal intervals. The increment 


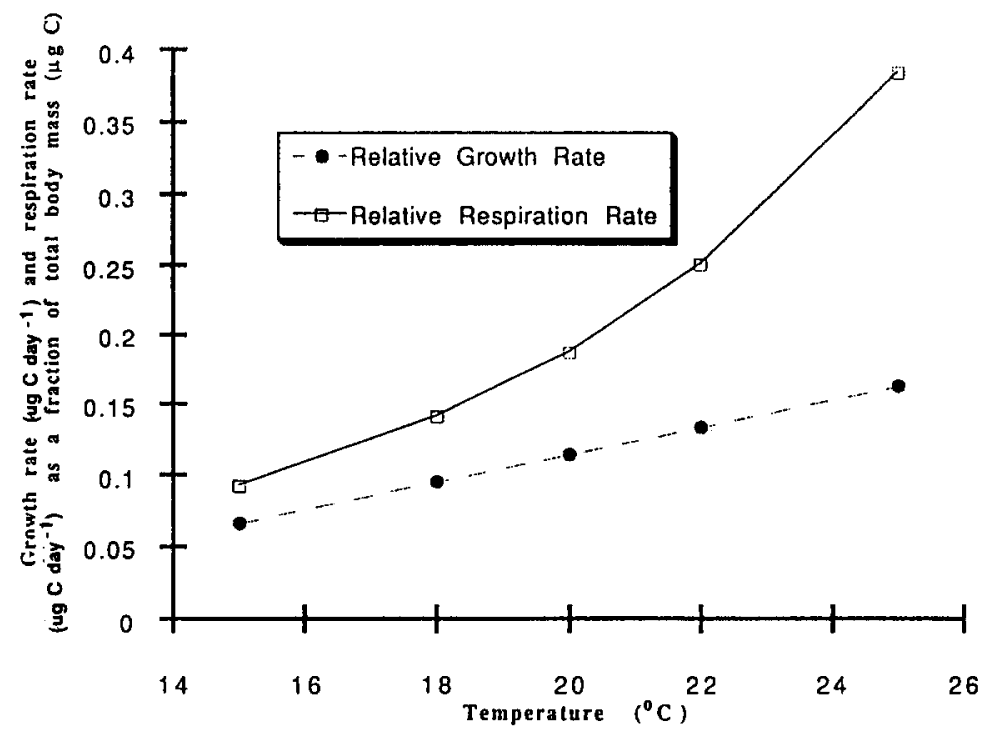

Figure 1. Minimum ingestion rate ( $\mu \mathrm{g} \mathrm{C}$ day $\left.^{-1}\right)$, amount of carbon a Chaoborus larva must ingest to account for respiratory and growth costs, as a function of total body mass $(\mu \mathrm{g} \mathrm{C})$ at different temperatures $\left({ }^{\circ} \mathrm{C}\right)$ and at different stages in development.

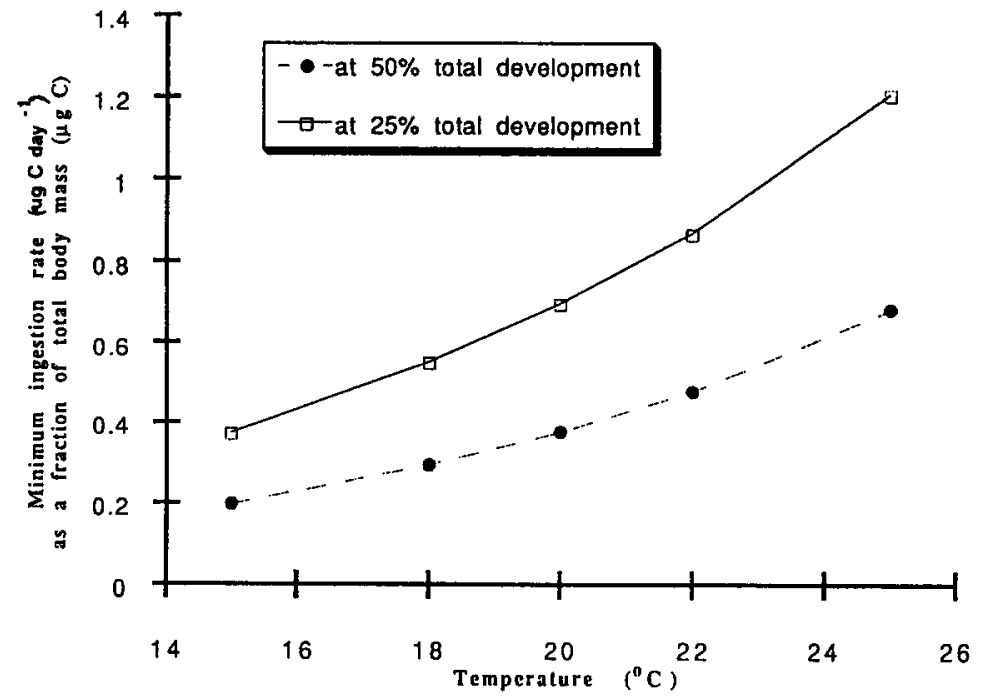

Figure 2. Respiratory $\left(\mu \mathrm{g} \mathrm{C} \mathrm{day}^{-1}\right)$ and growth $\left(\mu \mathrm{g} \mathrm{C}\right.$ day $\left.^{-1}\right)$ rates relative to body mass $(\mu \mathrm{g} \mathrm{C})$ at different temperatures $\left({ }^{\circ} \mathrm{C}\right)$ for $\mathrm{Chaoborus}$ larvae at $50 \%$ total development.

in body carbon over each interval was calculated by Eq. 6. We thus calculated a discrete measure of growth for each interval of development time.

\section{Results}

Minimum ingestion rate, the amount of carbon that a larva must ingest to account for respiration and growth requirements, increases with temperature as a function of body mass (Figure 1). The rate at which ingestion rate as a function of total body carbon increases with temperature is much more rapid for a larva at $25 \%$ total development than for a larva at $50 \%$ total development. The percentage of body mass that a larva must ingest each day increases more rapidly with temperature for larvae in early stages of development. 


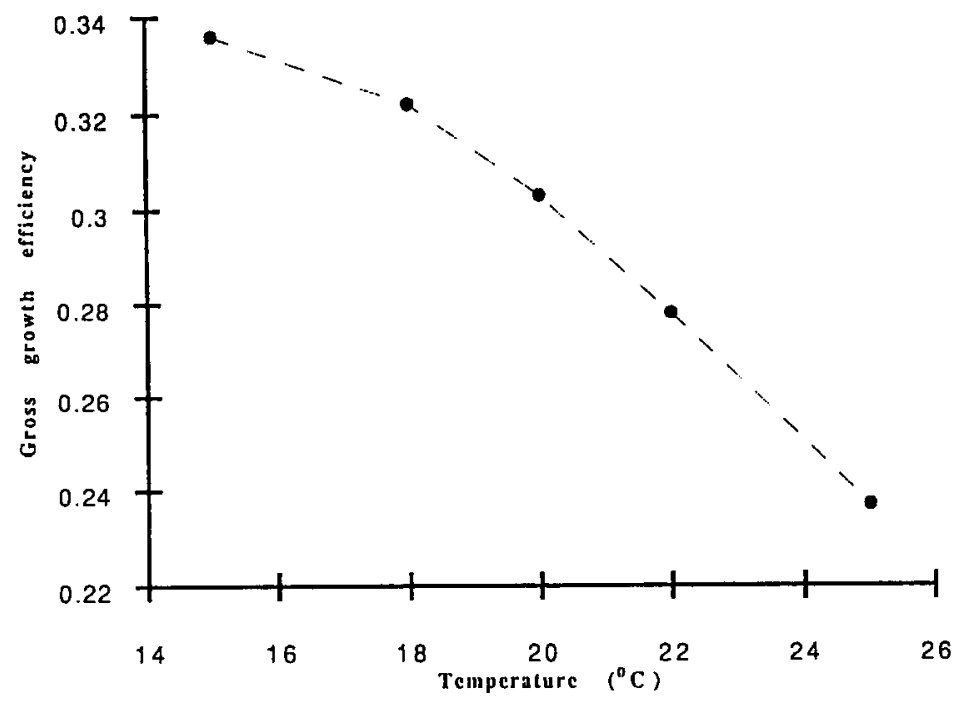

Figure 3. Gross growth efficiency (growth rate/ingestion rate), as a function of temperature $\left({ }^{\circ} \mathrm{C}\right.$ ), for Chaoborus larvae at $50 \%$ total development.

Table I. MTS (mean time to starvation in days), amount of time for a non-feeding Chaoborus larva to respire $50 \%$ of its body mass ( $\mu \mathrm{g} \mathrm{C}$ ), for each instar at different temperatures $\left({ }^{\circ} \mathrm{C}\right)$

\begin{tabular}{llllll}
\hline Instar & $15^{\circ} \mathrm{C}$ & $18{ }^{\circ} \mathrm{C}$ & $20^{\circ} \mathrm{C}$ & $2{ }^{\circ} \mathrm{C}$ & $25^{\circ} \mathrm{C}$ \\
& MTS (SE) & MTS (SE) & MTS (SE) & MTS (SE) & MTS (SE) \\
\hline I & $2.3(0.43)$ & $1.5(0.28)$ & $1.2(0.21)$ & $0.9(0.16)$ & $0.6(0.10)$ \\
II & $3.4(0.72)$ & $2.2(0.47)$ & $1.7(0.35)$ & $1.3(0.26)$ & $0.8(0.17)$ \\
III & $4.8(0.89)$ & $3.1(0.58)$ & $2.3(0.44)$ & $1.8(0.33)$ & $1.2(0.21)$ \\
IV & $6.0(0.43)$ & $3.9(0.28)$ & $2.9(0.21)$ & $2.2(0.16)$ & $1.4(0.10)$
\end{tabular}

Respiration and growth rates as functions of body mass both increase with temperature (Figure 2). For a larva at $50 \%$ total development, growth rate increases nearly linearly with temperature and respiration increases at an exponential rate. At low temperatures, respiration and growth increases with temperature at about the same rate, but at high temperatures respiration rate increases much faster with temperature than does growth rate.

Gross growth efficiency, growth rate/ingestion rate, of a Chaoborus larva at 50\% total development decreases with increasing temperature (Figure 3). Less carbon is allotted for growth at higher temperatures.

Mean time to starvation, calculated subjectively as the amount of time for a non-feeding Chaoborus larva to lose $50 \%$ of its body mass, decreases with increasing temperature (Table 1). Young larvae are more likely to starve when not eating for a short period than are older larvae. At tropical lake temperatures $\left(25^{\circ} \mathrm{C}\right)$, the minimum estimated starvation time for larvae at $25 \%$ total development is less than one day.

\section{Discussion}

Chaoborus larvae in high water temperature environments have to eat much more food each day in order to survive than do larvae inhabiting water of lower temperatures. Thus, larvae living in warm temperature water have to spend more time capturing and ingesting food items. Chaoborus larvae living at high temperatures are probably forced to be more active for a greater period each day than are chaoborids living at lower temperatures. Increasing the amount of energy spent on activity may reduce the amount of energy available for growth. Ratte (1984) found that as temperature increases, the final adult size of Chaoborus crystallinus decreases. With an increase in temperature, growth may be hindered.

Our model assumes that temperature governs the schedule of development for Chaoborus larvae. Because chaoborids have a synchronous emergence period, a fixed period of time is allotted for larval growth and development. For most insects, as body size increases, fecundity and reproductive success increase as well (Thornhill \& Alcock, 1983). It will be advantageous for a Chaoborus larva to achieve the largest size possible, conferring greater reproductive success, before emerging as an adult. Growth requires food, 
and food is up in the water column as are predators. Chaoborus larvae must risk predation when feeding.

If Chaoborus larvae at high temperatures have to remain active for most of each day to obtain sufficient food for survival and growth, foraging larvae may be more susceptible to fish predation than larvae remaining in the sediments. Chaoborus larvae in tropical systems may chance death by predation over death by starvation. Fish predation is generally recognized as a likely cause for the suppression or extinction of larger, visible members of the planktonic community in lentic systems. Gliwicz (1985) reasoned that the disappearance of Daphnia lumholtzi from a tropical reservoir was due to the interaction between fish predation and starvation. Intense predation forced the Daphnia into food limited refuges where they eventually starved. Chaoborus larvae in tropical systems similarily face the risk of starvation if they do not feed; thus, the larvae may have to risk exposure to predators in order to obtain food.

As temperature increases, younger larvae must ingest a greater percentage of their body weight than most older larvae. First and second instar larvae may be under extreme stress to consume enough food to fuel their metabolism and growth at high temperatures. Larvae consuming less carbon than needed for respiratory costs must catabolize carbon reserves in the body.

It is possible that even in systems where Chaoborus is absent, eggs are occasionally introduced by natural means. Populations may not become established because energetic constraints due to temperature and oxygen levels may be too great for the young larvae to survive for more than a few days. Conditions of temporary anoxia may prevent Chaoborus populations from establishing or persisting in new environments, particularly if abundant planktivorous fish eliminate them from oxygenated, food-rich regions.

High, constant temperatures are characteristic of tropical, lentic systems. Larvae in tropical systems are constantly exposed to high temperatures, unable to enter an 'metabolic refuge' like that of the lower temperature hypolimnion of temperate systems. Chaoborus larvae in tropical systems are constantly running full speed ahead towards emergence, with little time or energy for interruptions. It is possible that Chaoborus may enter certain systems where energetic constraints are too great for a population to establish. The interaction between oxygen content of the water, fish predation, food levels and ability of Chaoborus to survive is a fine line at high temperatures. Low levels of oxygen and limited access to food may prevent
Chaoborus larvae from taking refuge from fish predation in bottom areas. High temperatures, predation risk, and low oxygen conditions may interact to limit the distributions of Chaoborus in the great lakes region of East Africa.

\section{References}

Berg, K. \& P. M. Jonasson, 1965. Oxygen consumption of profundal lake animals at low oxygen content of the water. Hydrobiologia 26: 131-143.

Downing, J. A. \& F. H. Rigler, 1984. A manual for the assessment of secondary productivity in fresh waters. Blackwell Scientific Publications, Boston.

Eccles, D. H., 1985. Lake flies and sardines - a cautionary note. Biol. Conserv. 33: 309-333.

Giguere, L. A., 1981. Food assimilation efficiency as a function of temperature and meal sizes in larvae of Chaoborus trivittatus (Diptera: Chaoboridae). J. Anim. Ecol. 50: 103-109.

Gliwicz, Z. M., 1985. Predation or food limitation: an ultimate reason for extinction of planktonic cladoceran species. Arch. Hydrobiol. 21: 419-430.

Hecky, R. E. \& H. J. Kling, 1987. Phytoplankton ecology of the great lakes in the rift valley of Central Africa. Arch. Hyrobiol. Beih. Ergebn. Limnol. 25: 197-228.

Larow, E., 1970. The effect of oxygen tension on the vertical migration of Chaoborus larvae. Limnol. Oceanogr. 15: 357-362.

Lehman, J. T., 1995. Pelagic food webs of the East African Great Lakes In T. C. Johnson \& E. Odata (eds), Limnology, Climatology, and Paleolimnology of the East African Lakes. Jing, Uganda.

Lewis, W. M., 1975. Distribution and feeding habits of a tropical Chaoborus population. Verh. Int. Ver. Limnol. 19: 3106-3119.

MacDonald, W. W., 1956. Observations on the biology and behavior of chaoborids and chironomids in Lake Victoria and on the feeding habits of the 'elephant-snout' fish (Morymyrus kannume Forsk). J. Anim. Ecol. 25: 36-53.

McGowan, L. M., 1974. Ecological studies on Chaoborus (Diptera, Chaoboridae) in Lake George, Uganda. Freshwat. Biol. 4: 483505.

Northcote, T. G., C. J. Walters \& J. M. B. Hume, 1978. Initial impacts of experimental fish introductions on the macrozooplankton of small oligotrophic lakes. Verh. Int. Ver. Limnol. 20: 2003-2012.

Peters, R. H., 1983. The ecological impacts of body size. Cambridge University Press, New York.

Pope, G. f., J. C. H. Carter \& G. Power, 1973. The influence of fish on the distribution of Chaoborus spp. (Diptera) and density of larvae in the Matamek River system, Quebec. Trans. Am. Fish. Soc. 102: 707-714.

Ratte, H. T., 1984. Temperature and Insect Development. In K. H. Hoffman (ed.), Environmental Physiology and Biochemistry of Insects. Springer Verlag, Berlin.

Stahl, J. B., 1966. The ecology of Chaoborus in Myers Lake, Indiana. Limnol. Oceanogr. 11: 177-183.

Swift, M. C., 1976. Energetics of vertical migration in Chaoborus trivittatus larvae. Ecology 57: 900-914.

Thornhill, R. \& J. Alcock, 1983. Evolution of Insect Mating Systems. Harvard University Press, Cambridge, Mass. 